\title{
CONTRIBUIÇÕES DA GEOGRAFIA ECONÔMICA EVOLUCIONÁRIA PARA A COMPREENSÃO DA DINÂMICA INOVATIVA
}

\section{Nome e filiação:}

Rafael Stefani, Mestre em Economia pela Universidade do Vale do Rio dos Sinos (Unisinos).

Janaina Ruffoni, Doutora em Política Científica e Tecnológica pela Universidade Estadual de Campinas (Unicamp), professora do Programa de Pós-Graduação em Economia da Universidade do Vale do Rio dos Sinos (Unisinos).

\section{Resumo:}

O ambiente econômico atual traz a mudança técnica como elemento dependente da topologia relacional dos atores e do arranjo instalado de firmas e instituições no território, que assume um protagonismo, não sendo mais tratado como um elemento passivo. As aglomerações industriais inovadoras são explicadas pela geração e troca de conhecimento, sendo interdependentes das redes sociais e dos contextos institucionais e locais. A perspectiva evolucionista em geografia econômica ocupa-se com a formação da paisagem econômica e entende que as experiências e as competências aprendidas por indivíduos em determinada localidade ao longo do tempo pode determinar o presente e a trajetória futura do espaço e provocar uma mudança competitiva. Considerando esse cenário, o artigo objetiva apresentar a área da Geografia Econômica Evolucionária e propor uma reflexão para compreender se e como esta auxilia na análise da mudança técnica. O resultado apresenta a Geografia Econômica Evolucionária com uma fertilidade intelectual importante para o entendimento da dinamica inovativa e da transformação do cenário técnico de regiões.

Palavras Chave: Geografia Econômica Evolucionária, dinâmicas de proximidade, inovação.

\begin{abstract}
:
The current economic environment brings technical change as an element dependent on relational topology of the actors and the installed arrangement of firms and institutions in the territory, which plays a role, no longer treated as a passive element. Innovative industrial clusters are explained by the generation and exchange of knowledge, being interdependent social networks and institutional and local contexts. The evolutionary perspective on economic geography is concerned with the formation of the economic landscape and understand that the experiences and skills learned by individuals in a given location over time can determine the present and the future path of space and cause a competitive change. Given this scenario, the article presents the area of Evolutionary Economic Geography and propose a reflection to understand if and how this assists in technical change analysis. The result shows the Evolutionary Economic Geography with an important intellectual fertility for understanding the dynamics and innovative transformation of the technical scenario regions.
\end{abstract}

Key-words: Evolutionay Economic Geography, proximity dynamics, innovation.

Área ABEIN: Área 5

JEL Classification: O, O3, O43 


\title{
Contribuições da Geografia Econômica Evolucionária para a compreensão da dinâmica inovativa
}

\begin{abstract}
Rafael Stefani ${ }^{1}$
Janaina Ruffoni ${ }^{2}$

\section{Resumo}

O ambiente econômico atual traz a mudança técnica como elemento dependente da topologia relacional dos atores e do arranjo instalado de firmas e instituições no território, que assume um protagonismo, não sendo mais tratado como um elemento passivo. As aglomerações industriais inovadoras são explicadas pela geração e troca de conhecimento, sendo interdependentes das redes sociais e dos contextos institucionais e locais. A perspectiva evolucionista em geografia econômica ocupa-se com a formação da paisagem econômica e entende que as experiências e as competências aprendidas por indivíduos em determinada localidade ao longo do tempo pode determinar o presente e a trajetória futura do espaço e provocar uma mudança competitiva. Considerando esse cenário, o artigo objetiva apresentar a área da Geografia Econômica Evolucionária e propor uma reflexão para compreender se e como esta auxilia na análise da mudança técnica. O resultado apresenta a Geografia Econômica Evolucionária com uma fertilidade intelectual importante para o entendimento da dinamica inovativa e da transformação do cenário técnico de regiões.
\end{abstract}

Palavras Chave: Geografia Econômica Evolucionária, dinâmicas de proximidade, inovação.

\begin{abstract}
The current economic environment brings technical change as an element dependent on relational topology of the actors and the installed arrangement of firms and institutions in the territory, which plays a role, no longer treated as a passive element. Innovative industrial clusters are explained by the generation and exchange of knowledge, being interdependent social networks and institutional and local contexts. The evolutionary perspective on economic geography is concerned with the formation of the economic landscape and understand that the experiences and skills learned by individuals in a given location over time can determine the present and the future path of space and cause a competitive change. Given this scenario, the article presents the area of Evolutionary Economic Geography and propose a reflection to understand if and how this assists in technical change analysis. The result shows the Evolutionary Economic Geography with an important intellectual fertility for understanding the dynamics and innovative transformation of the technical scenario regions.
\end{abstract}

Key-words: Evolutionay Economic Geography, proximity dynamics, innovation.

JEL Classification: O, O3, O43

\section{Introdução}

Já é bem suportado pela literatura que a inovação não se configura como um elemento linear e de fácil compreensão. Na verdade, a inovação assumiu um papel central na competitividade dinâmica, que pouco tem a ver com vantagens competitivas tradicionais, ditas de caráter estático e ligadas à exploração exaustiva dos recursos humanos e naturais ou ao apelo da taxa de câmbio manipulada para uma inserção

${ }^{1}$ Mestre em Economia pela Universidade do Vale do Rio dos Sinos (Unisinos). E-mail: rafstefani@gmail.com

${ }^{2}$ Doutora em Política Científica e Tecnológica pela Universidade Estadual de Campinas (Unicamp), professora do Programa de Pós-Graduação em Economia da Universidade do Vale do Rio dos Sinos (Unisinos). E-mail: jruffoni@unisinos.br / janainart@gmail.com 
espúria no cenário internacional. Para a construção de uma competitividade sistêmica, são privilegiadas as vantagens competitivas de caráter dinâmico, que dependem da introdução, desenvolvimento e uso de inovações de cunho tecnológico, organizacional e de gestão no quotidiano das atividades econômicas.

Nesse contexto, o território assume um papel protagonista, não mais sendo considerado um ator passivo. Esta é uma visão dos novos enfoques adotados pelas teorias e políticas de desenvolvimento local, que apostam na condição do território como elemento facilitador de transformação da realidade social e estão ligados às potencialidades empresariais e produtivas nele encontradas. A inovação resultaria de um processo de aprendizado de caráter cumulativo e virtuoso, estabelecendo a relação entre aglomeração industrial e modernização tecnológica dependente de redes locais de cooperação, políticas públicas, traços culturais, institucionais e históricos, que em conjunto definem a potencialidade de determinado território. Em outros termos, o desenvolvimento bem sucedido de determinadas regiões é capaz de fomentar uma articulação endógena e formar uma paisagem que desenvolva condições competitivas de longo prazo. (BRINCO, 2010).

Uma parte do processo de transferência de conhecimento e tecnologias envolve os chamados conhecimentos tácitos que não estão embutidos nos projetos e forma o conteúdo que é mais dificilmente repassado (somente pelo contato face-a-face), o que traz implicações quanto aos tempos e aos investimentos requeridos nos processos de absorção de conhecimento e tecnologia. Partindo do pressuposto que o conhecimento assume postura central, entende-se que a geografia exerce influência significativa na maneira como este é disseminado, já que é plausível compreender que a distância entre atores dificulta ou facilita o acesso à interação e troca. Considerando essa lógica que a geografia da inovação ocupa seus estudos, centrados na análise do comportamento da troca de conhecimento entre agentes e sua influência na dinâmica inovativa.

A corrente neoschumpeteriana (ou evolucionária) entende que as transformações costumam ser dependentes da firma, do seu aprendizado e de suas relações, já que firmas não inovam apenas com os seus recursos internos, mas dependem também de fontes externas e da disponibilidade de um ecossistema conjugado que intensifica e auxilia o processo inovativo. (ARAÚJO, 2013; GONÇALVES; FAJARDO, 2011; RUFFONI, 2015).

Howells (2002) argumenta que a geografia influencia centralmente na atividade do conhecimento. O conhecimento é individual e influenciado pelos desenvolvimentos cognitivo, social, cultural e pelas circunstâncias econômicas, que por sua vez são influenciadas pelo local. Associado a isso, o desenvolvimento do conhecimento coletivo (ou do estoque de conhecimento local) é determinado pela interação humana, que é forjada pelo ambiente e dependente das diferentes distâncias. Logo, ao perceber a importância dessa área de estudo para o aprofundamento da dinâmica inovativa é que a Geografia ganha mais espaço dentro da Economia.

Do ponto de vista teórico é bem aceito na literatura que alguns trabalhos exerceram influências consideráveis na geografia econômica ou na economia regional. Em certa medida, pode-se citar os trabalhos de Johann HeinrichVon Thünen (1826), Alfred Weber (1909), Walter Christaller (1933), August Lösch (1940) e Walter Isard (1956) onde o espaço era entendido como um obstáculo aos transportes e como um fator de produção. Dos anos 1850 aos anos de 1920 quando algum efeito econômico está ligado ao espaço, esse efeito é atribuido às economias externas de Alfred Marshall (1890). A economia espacial só se desenvolve na Alemanha e nos países escandinavos com Claude Ponsard (1958). Há também intelectuais que avançam com ênfase nos fatores de aglomeração, e dentro desse arcabouço cabe citar François Perroux (1955), Gunnar Myrdal (1957) e Albert Hirshman (1958)².

A partir de 1980 surge uma nova geografia econômica, mais sensível ao papel da inovação e a dinâmica do progresso técnico. Para serem reconhecidos, esses resultados precisavam ser formalizados e os economistas Paul Krugman, Masahisa Fujita e Anthony Venables se encarregaram, seminalmente, de analisar o espaço geográfico, o desenvolvimento econômico, os rendimentos crescentes e o comércio interno e externo.

Em 2005 a Geografia Econômica Evolucionária (GEE) emerge e procura desenvolver seus trabalhos influenciados pelas ideias neoschumpeterianas. Essa corrente afirma que existe uma forma

\footnotetext{
${ }^{3}$ Para uma leitura compilada sobre a história do pensamento econômico regional e sua articulação com o espaço sugere-se: Cruz et al. (2011).
} 
desigual de desenvolvimento entre regiões, e sua explicação está centrada no indivíduo e em suas relações com o entorno. Ademais, a explicação pode residir na proximidade geográfica existente entre os agentes, isto é, para ocorrer a interação entre atores e a troca de conhecimento, a proximidade passa a ser um prérequisito que pode facilitar ou dificultar a relação. Em suma, a evolução das estruturas sociais formadas pelos atores (endogenamente) pode afetar a relação que determina (ou não) os fluxos de conhecimento entre agentes.

Considerando o exposto, o objetivo do artigo é apresentar a área da Geografia Econômica Evolucionária e propor uma reflexão para compreender se, e como, esta contribui para a análise da mudança técnica. Para tanto, o artigo está dividido em quatro seções incluindo essa introdução. Na segunda parte apresenta-se a corrente Geografia Econômica Evolucionária (GEE), suas ideias e divergências intelectuais com as novas correntes da geografia (Nova Geografia Econômica e Geografia Econômica Institucional). Na terceira seção aprofunda o conceito das dinâmicas de proximidade que trata de seu papel nas relações sociais e na dinâmica inovativa. A quarta parte é destinada à discussão e avaliações.

\section{Geografia Econômica Evolucionária}

O ponto de vista evolucionário dentro da economia geográfica procura nutrir seus conceitos tendo como crença que as competências e as experiências adquiridas ao longo do tempo por indivíduos e entidades em regiões particulares são capazes de determinar as paisagens presentes, assim como podem influenciar na trajetória futura da região. Essencialmente, a ideia dessa corrente está incorporada nas realidades socioeconômicas que impulsionam a busca contínua pela novidade e pela vantagem competitiva. A mudança tecnológica surge endogenamente, através de mecanismos de transformação e adaptação que moldam a evolução da economia no espaço. A consequência é que a paisagem econômica está em constante agitação, empurrada e puxada por processos de concorrência que criam trabalho e rotinas dentro de alguns setores e regiões e, ao mesmo tempo, incentivam a experimentação e a descoberta em outros, resultando em uma geografia desigual de produção de conhecimento e inovação. Assim, a mudança tecnológica tem também uma dimensão decididamente geográfica que afeta o crescimento econômico e a prosperidade regional.

Em suma, a corrente evolucionária geográfica está interessada na produção e na destruição de novidades no espaço e na ligação entre inovação e crescimento regional. (BOSCHMA; MARTIN, 2010). Para a Geografia Econômica Evolucionária (GEE), a criação de conhecimento tecnológico é um movimento e uma recombinação entre agentes e instituições que definem, de forma central, a evolução no espaço econômico regional. A GEE procura focar as relações entre os agentes e as instituições ao invés de contar com a região como aspecto único de unidade de análise. Ademais, certas análises consideram as firmas ou atividades públicas como lócus do desenvolvimento e da mudança econômica. Para a GEE, a evolução econômica é entendida como o resultado do direcionamento da inovação que é organizada pelas rotinas e a seletiva transmissão entre agentes e instituições. Enquanto geógrafos econômicos têm explorado a economia gerada em aglomerações e a produção e disseminação de conhecimento que ocorre em alguns lugares em vez de outros, pouco ainda é conhecido sobre o surgimento dessas aglomerações, como ocorre sua alteração ao longo do tempo e quais firmas ou agentes econômicos são mais suscetíveis para capturar diferentes retornos para co-localização. Em síntese, a agenda de pesquisa da GEE tem como ambição descortinar a evolução espacial de empresas, indústrias, redes, cidades e regiões, além de processos elementares tais como a entrada, o crescimento, o declínio e a saída de empresas e seu comportamento locacional. (KOGLER, 2015).

Para abrir a caixa preta e encontrar as forças do diversificado desenvolvimento regional em várias escalas (micro - meso - macro nível), a GEE está centrada em três esforços de pesquisa: primeiro, o conceito de Darwinismo Generalizado, especialmente os conceitos de busca, seleção, variedade e retenção (NELSON, 1995); segundo, a Teoria da Complexidade, intimamente ligada ao comportamento estocástico cujo foco essencial é a pesquisa dos sistemas dinâmicos não-lineares atribuindo propriedades 
não-teleológicas, entendendo que os micro-componentes interagem de forma constante e influenciam as decisões em diferentes dimensão e alcance, formando um sistema complexo que transforma a estrutura e o comportamento da região. (MARTIN; SUNLEY, 2010). O terceiro esforço de pesquisa é a influência geográfica nas interações de conhecimento (knowledge spillovers) em que o contexto ocupa um papel determinante na difusão do conhecimento através das relações entre indivíduos. (HOWELLS, 2002).

Com base nesses fundamentos, a lógica é que a troca de conhecimento flui de forma mais eficaz entre semelhantes, ou seja, peças relacionadas no sistema. Assim, se a troca de conhecimento é de fato limitada por algum tipo de proximidade (cognitiva, social, geográfica, institucional ou organizacional), a expectativa é que o conjunto existente de composição de tecnologia, juntamente com o estoque de conhecimento em um determinado tempo e lugar moldem a trajetória futura da região. Enquanto esta lógica de dependência de trajetória sugere que há limitações significativas na medida em que um sistema pode ficar aprisionado devido ao lock-in tecnológico (pelo menos no curto prazo), isso também indica que existem potenciais oportunidades para o conhecimento relacionado ${ }^{4}$, ou domínio de uma nova tecnologia que não faz parte do estoque de conhecimento presente da região. (KOGLER, 2015).

A GEE está posicionada como um substrato de duas importantes vertentes teóricas dentro do campo econômico: a Nova Geografia Econômica (NGE) e a Geografia Econômica Institucional (GEI). A primeira vertente empresta para a GEE a metodologia dedutiva incorporada nos modelos formais, mesmo que tratada de forma diferente. Contudo, a GEE considera a evolução espacial dos setores e as relações entre indivíduos uma dinâmica co-evolucionária, considerando o espaço em regiões com interações múltiplas. A segunda vertente traz a característica indutiva (teoria apreciativa), além dos conceitos de rotina, racionalidade limitada, busca pelo desequilíbrio, influência histórica (path dependence), entendendo que a tecnologia avança de forma diferente entre regiões ao longo do tempo, como reflexo da coevolução dos agentes e instituições.

A Nova Geografia Econômica ${ }^{5}$ (NGE) que reacendeu o debate entre geógrafos ligados à economia quando abriu uma nova agenda de pesquisa aliando contribuições da ciência regional, teoria da localização e elementos derivados do conceito central da microeconomia tradicional. A NGE, que tem como referência Krugman, Venables e Fujita, pode ser considerada uma extensão recente do pensamento neoclássico para explicar a aglomeração, especialização e o comércio entre agentes ou nações partindo do pressuposto básico das decisões racionais e do conceito de optimalidade. (BOSCHMA; FRENKEN, 2006) $)^{6}$.

Assumindo retornos crescentes de escala e competição imperfeita em nível das firmas, a NGE considera modelos em que o nível de transporte ou os custos de transação dos bens são os parâmetros. (BRAKNMAN; GARRETSEN, 2003). Essa corrente trabalha com modelos formais e essência dedutiva, assumindo pressupostos de maximização da utilidade e racionalidade absoluta e utiliza a lógica de atração do equilíbrio para gerar conclusões e proposições. Além disso, os pressupostos não aceitam a existência de diferença entre regiões, existindo apenas as divergências entre o fator preço e arranjos institucionais. $\mathrm{O}$ modelo inicia sua análise partindo da posição de um espaço neutro com o objetivo de explicar como a aglomeração pode ocorrer a partir dessa situação, demonstrando como as desigualdades espaciais podem emergir de uma paisagem em branco, em um mundo uniforme. (BOSCHMA; FRENKEN, 2006).

Mesmo contendo diferenças teóricas estruturais, a NGE possui elementos que são inseridos no arcabouço da GEE para auxiliar na compreensão do mecanismo dinâmico da criação e da trasformação desigual das regiões. Essa aproximação está centrada na metodologia dos modelos, incluindo a

\footnotetext{
4 O termo conhecimento relacionado aparece na literatura da GEE como elemento chave para a diversificação e desenvolvimento de novas trajetórias de conhecimento. Isso ocorre com a recombinação entre recursos existentes e novas tecnologias desenvolvidas de diferentes indústrias. Para aprofundamentos sobre essa perspectiva sugere-se Beaudry e Schiffauerova (2009) e Boschma (2015).

5 O debate sobre o rótulo Nova Geografia Econômica ainda não está superado apesar de ganhar contornos mais consensuais na última década. Alguns pesquisadores preferem o termo Economia Geográfica defendendo a necessidade de inserir mais geografia no mainstream econômico. Para um maior aprofundamento sobre essa perspectiva sugere-se Fujita e Thisse. (2002).

${ }^{6}$ Para uma leitura compilada sobre as divergências e influências na história da geografia no campo da economia, bem como a falta de diálogo que poderia auxiliar na evolução da disciplina sugere-se Cotelo et al. (2014).
} 
possibilidade de enclausuramento tecnológico (lock-in) e a irreversibilidade dos processos. (BOSCHMA; FRENKEN, 2006). Por outro lado, a NGE (assim como a GEE) assume em seus modelos a possibilidade do equilíbrio múltiplo, no qual a trajetória dos processos indica um dos possíveis equilíbrios, e a irreversibilidade das ações pode levar o sistema ao lock-in e resultados sub-ótimos. (BOSCHMA; LAMBOOY, 1999).

Outra característica comum entre as duas correntes é a capacidade explicativa dos modelos. Para a NGE as aglomerações ocorrem quando consumidores e firmas preveem a vantagem de alocação em aglomerados em razão da redução dos custos de transporte e da maximização dos lucros. Preocupação similar ocupa a agenda da GEE, porém considerando outra lógica. Assumindo como ponto incial a geração de uma firma, e entendendo que essa firma possui uma probabilidade de criar uma nova firma, o resultado dessa dinâmica locacional pode ser modelado como um processo estocástico, e indica que as ações passadas influenciam nas atividades presentes e futuras. O modelo estocástico também pode ser aplicado para a evolução espacial das conexões entre os agentes locais (nível micro), na qual novas conexões podem ser observadas. Esses links ocorrem em qualquer tempo e lugar e são dependentes do espaço geográfico e das conexões preferenciais. ${ }^{7}$ (BARABÁSI, 2002). A mesma lógica é percebida no modelo de ciclo de vida da indústria (KLEPPER, 2002), que revela a maior probabilidade de sobrevivência dos primeiros (firmas) entrantes comparados aos últimos em razão do tempo de desenvolvimento das rotinas e da maturidade de seus relacionamentos (conexões).

Apesar das similaridades entre as correntes, é necessário deixar claro suas divergências fundamentais. Primeiro diferentemente da NGE que explica a emergência das distribuições regionais desiguais através de modelos que assumem os conceitos de maximização e agente homogêneo, a GEE está baseada em um conjunto de suposições que inclui racionalidade limitada (SIMON, 1955), rotinas e heterogeneidade entre agentes. (NELSON, 1995). Enquanto a NGE assume a concorrência monopolística como estrutura de análise, a GEE tem como elemento de estudo a entrada, a saída e a inovação coevoluindo endogenamente com o mercado $^{8}$. (BOSCHMA; FRENKEN, 2006).

Segunda divergência que merece destaque diz respeito ao nível econômico de agregação. A NGE aborda a economia espacial no nível macro em termos de decisão de localização do agente (firmas e consumidores) e, no nível micro, assume determinada estrutura de mercado previamente forjada pela microeconomia. Dessa forma, a NGE é incapaz de informar onde a localização industrial e a especialização ocorrem ou por que ocorre em determinados lugares e não em outros. Em contraste, a GEE tem como objetivo entender a evolução espacial das indústrias no nível meso. Logo, a evolução espacial do sistema econômico no nível macro é abordada em um quadro de mudança estrutural em que a unidade territorial é analisada em termos de ascensão e queda dos setores e redes de infraestrutura, seja em países, regiões ou cidades. (BOSCHMA; FRENKEN, 2006).

Terceira divergência: os modelos da NGE interpretam e refletem a formação e aglomeração no tempo adotando a análise estática de equilíbrio. A mudança de equilíbrio é causada por parâmetros exógenos como, por exemplo, a queda nos custos de transporte ou a redução de barreiras ao comércio. $\mathrm{O}$ modelo proposto pela GEE está centrado na dinâmica econômica que mostra temporariamente a direção de convergência determinada endogenamente pelo comportamento inovativo da firma. Em outros termos, isso implica que crescimento e declínio de firmas, setores e territórios sejam modelados explicitamente pelo tempo, assumindo o caráter estocástico oculto que reflete a inovação. (BOSCHMA; FRENKEN, 2006).

\footnotetext{
7 O termo conexões preferenciais indica que atores (nós) preferem se relacionar (conectar) com atores (nós) mais bem relacionados (conectados) para tirar proveito da rede. O resultado dessa topologia espacial pode ser entendido como uma rede de estrutura estocástica que tende a concentrar as conexões em determinados atores formando uma espécie de hub com grande concentração. Um hub é capaz de atrair os novos atores que entram na rede dado sua complexidade relacional ou conexão preferencial. Para um maior aprofundamento sobre essa perspectiva sugere-se Barabási (2002), especialmente o capítulo sétimo: os ricos ficam mais ricos.

8 Sob esse aspecto alguns autores admitem que a Nova Geografia Econômica apresenta fracas fundações considerando as teorias da moderna organização industrial. Para um maior aprofundamento sobre essa perspectiva sugere-se Neary (2001).
} 
Uma diferença final diz respeito à teoria subjacente da economia de aglomeração. A NGE confia sua explicação aos rendimentos crescentes de escala (internos à firma). A GEE está interessada nas aglomerações decorrentes dos efeitos dos transbordamentos de conhecimento (knowledge spillovers) ${ }^{9}$. Em uma perspectiva evolucionária, o transbordamento de conhecimento contribui para o autorreforço das economias de aglomeração com o qual as firmas de localização em uma região geram e atraem, através da criação de conhecimento, novas firmas para a mesma região. Ao mesmo tempo, os transbordamentos de conhecimento podem ser responsáveis pela difusão e trajetória da tecnologia gerada em uma determinada região impulsionada pela proximidade de firmas estabelecidas em aglomerados locais ${ }^{10}$.

Em suma, a GEE entende que a construção do cenário geográfico parte da interação dinâmica dos agentes ao longo do tempo. A característica determinante está na coevolução dos atores (micro - macro meso) que é realizada de forma estocástica e não determinística. Para entender a evolução, essa corrente partilha das concepções matemáticas de modelagem e descarta o princípio de racionalidade absoluta e equilíbrios estáticos.

\subsection{Interface com a Geografia Econômica Institucional}

Na atualidade, há cada vez mais o concenso sobre a importância das instituições no campo econômico. O argumento por trás dessa afirmação é a dificuldade de se captar o amplo processo de desenvolvimento sem levar em consideração o papel das instituições e seu desempenho. No campo da geografia econômica não é diferente. Durante os anos 1950, a disciplina foi fortemente influenciada por modelos de tradição alemã, principalmente as ideias de Lösch. Por volta dos anos 1970, até metade dos anos 1980, houve um viés marxista e do materialismo histórico. A partir dos anos 1980, os geógrafos adotaram métodos influenciados pela chamada virada institucional ${ }^{11}$, que consiste na necessidade de inserir fatores políticos, sociais e culturais na análise da geografia. Essa nova fase é considerada por alguns pesquisadores como um ponto de transição na disciplina, que leva em consideração a atividade econômica social e institucionalmente inserida no contexto econômico e na formação da região. (AMIN; THRIFT, 2000).

O primeiro aspecto que merece atenção é que nem todos os pesquisadores inseridos no campo da Geografia Econômica Institucional (GEI) podem ser denominados evolucionários. Isto ocorre especialmente com os estudos que avaliam o impacto dos ajustes institucionais no desempenho econômico e que ignoram o aspecto da dinâmica, elemento central para os evolucionários.

Outro aspecto de conflito é quanto a sua ferramenta de análise. A GEE utiliza a modelização formal para derivar hipóteses e comprovações, enquanto a GEI descarta a priori o uso de modelos matemáticos. Nos estudos regionais, a GEI prefere análises qualitativas, sem o reducionismo proposto por modelos e com casos de estudos profundos, procurando se ocupar da multifacetada natureza do desenvolvimento regional. Essa posição leva a críticas de falta de rigor, falta de provas de hipóteses e conceitos mal definidos. Dessa forma, as contribuições institucionais da geografia econômica têm alguma importância no plano teórico ao propor novas explicações e mecanismos para o desenvolvimento regional. (BOSCHMA; FRENKEN, 2006).

O terceiro ponto ressaltado é o tratamento do contexto. O enfoque evolucionário inicia suas análises com as rotinas organizacionais em nível da firma, e os enfoques da GEI consideram as instituições em determinado nível territorial. Ambos reconhecem a importância do ambiente na tomada de decisão,

\footnotetext{
${ }^{9}$ Localized Knowledge Spillovers (LKS) pode ser definido como “[...] knowledge externalities bounded in space [...]” (BRESCHI; LISSONI, 2001, p. 8, grifo nosso).

${ }^{10}$ Esse ponto é particularmente importante já que apresenta uma divergência epistemológica entre a NGE e a GEE. Ocorre que na opinião de Krugman não é possível medir o transbordamento de informações, ou pelo menos não no nível de abstração exigido. Atualmente existe uma ampla literatura abordando o conceito knowledge spillovers. Sua discussão teve início pelo economista Alfred Marshall (1920) a partir da experiência dos distritos industriais da Inglaterra no século XIX (Trindade Marshalliana) e retomou forças com o estudo de Adam Jaffe (1993) que desenvolveu uma metodologia para mensurar a existência e importância dos fluxos de conhecimento para a economia. Para um maior aprofundamento sobre essa perspectiva sugere-se Araújo (2013) e Autant-Bernard (2002).

${ }^{11}$ Virada institucional foi o termo utilizado para a adoção de práticas que têm origem em outras correntes teóricas (especialmente as ciências sociais) dentro da geografia sem a preocupação da demarcação da sub-disciplina. Essas influências também podem ser encontradas na literatura como virada cultural ou virada relacional.
} 
eliminando o paradigma neoclássico de maximização de utilidade; por outro lado, as rotinas são específicas de cada empresa (microcontexto), resultado de experiências passadas, enquanto as instituições são específicas de determinadas comunidades e territórios que provêm de um macrocontexto. Dessa forma, o contexto institucional pode exercer uma influência considerável nas rotinas das firmas, ou, dito de forma diferente, as rotinas das firmas podem compartilhar muitas características de um sistema institucional, mas tenderão a diferir de um sistema para outro. Compreender a aptidão das rotinas requer uma análise das instituições como agente determinante do contexto. Então, de acordo com a visão evolucionária, as instituições podem formar o comportamento econômico na medida em que as rotinas não entrem em conflito com as instituições. Essas rotinas, por outro lado, são heterogêneas. Cada empresa desenvolve a sua rotina em um determinado ambiente institucional. Conclui-se, portanto, que considerar apenas o território como unidade de análise é problemático, pois deverá ser assumido como pressuposto que as rotinas são homogêneas de algum determinado local. Nas palavras de Boschma (2004 apud BOSCHMA, 2006, p. 288):

[...] territories can only be called relevant and meaningful units when the idea of routines and competences can be transferred from the organizational level to the regional level. In that respect, the region has become an entity on its own, providing intangible and non-tradable asset based on a unique knowledge and institutional base, which is not accessible for non-local firms. Only in those (quite exceptional) circumstances, one needs to understand the success and failure of firms through their local context [...].

Em suma, a GEE está centralmente interessada em entender se (e de que modo) a geografia importa na paisagem econômica, ao contrário de assumir, de forma teórica, que ela é relevante em todos os casos. A corrente evolucionária geográfica entende que tanto as teorias dos lugares reais propostas pela corrente institucional como as determinantes tradicionais (fator preço) propostas pela Nova Geografia Econômica não são capazes de explicar as diferenças regionais e seu desenvolvimento ao longo do tempo. A GEE se preocupa em entender os motivos que levam regiões com similar institucionalidade e fatores endógenos apresentarem diferentes taxas e modelos de crescimento. Logo, são os fatores endógenos e as instituições, em conjunto, que podem apresentar uma análise dinâmica em nível do setor e das relações nas quais o padrão de dependência e o autorreforço do comportamento local formam o núcleo da explicação. Como resultado, a GEE propõe que os lugares reais e suas movimentações ao longo do tempo surjam das ações dos agentes econômicos ao invés de serem determinados pelo comportamento dos lugares.

Finalmente, para a GEE um espaço se transforma, ao longo do tempo, em um espaço real, onde novas estruturas e setores são construídos e concentrados. Essa formação sofre uma influência histórica, dependente de seu passado e das ações coletivas dos indivíduos que montam uma base institucional e que é dinamicamente adaptada e transformada em uma verdadeira coevolução temporal. Então, para Boschma e Frenken (2006, p. 290) "[...] regional development is more about path dependence than place dependence, although some places may be better in renewing their institutions than others [...]”.

\subsection{Geografia Econômica Evolucionária: objetivo e escopo}

Metodologicamente, pode-se concluir que a GEE discorda da visão institucional que reluta em adotar modelos formais e testes estatísticos como proposições teóricas. Por outro lado, o pensamento geográfico econômico evolucionário aceita as ferramentas apreciativas inseridas nos estudos institucionais como alternativa de compreensão das análises da região, diferentemente da escola neoclássica. Da mesma maneira, é possível compreender que a GEE afasta a ideia do agente otimizador, de atração para o equilíbrio e análises centrada excessivamente no espaço neutro e custos de transporte. Para a GEE há o padrão de dependência e análises de vários equilíbrios possíveis e recursivos. Entende 
que a satisfação do agente é não depende exclusivametne de regras institucionais (macro-contextual) ou padrões utilitaristas (micro-contextual), mas sim de um contexto em que a satisfação do agente depende de elementos estruturais e individuais correlacionados a padrões específicos e de suas orientações locacionais.

A fim de demarcar o seu arcabouço intelectual, a GEE entende que as firmas não são vítimas da história no tempo e no espaço. Elas são vítimas de suas rotinas que podem ser alteradas de acordo com suas decisões, em uma interação entre a estrutura e os agentes que produzem a evolução dos espaços reais. Esse processo de nascimento, de crescimento e de morte de firmas e setores é que interessa para a GEE, assim como o processo de inovação e coevolução entre firmas, indústrias e instituições. Em geral, espera-se que a habilidade de uma firma em duplicar suas rotinas em diferentes contextos geográficos contribua para o seu crescimento. Se as rotinas se tornam o elemento determinante para as firmas se diferenciarem (inovarem) no mercado, elas também são consideradas estratégias sofisticadas pelas empresas que acabam replicando seus hábitos em diferentes territórios com intuito de expandir suas ações. É partindo do ponto de vista desse modelo de crescimento que a Geografia Econômica Evolucionária está centrada, e são duas as unidades de análise que a preocupam: a evolução espacial dos setores e as redes de relacionamento.

Primeiro, nos modelos evolucionários de formação de relações sociais o processo de entrada e de saída de agentes e a formação dinâmica de novas conexões (relações) podem ser mensurados com certa probabilidade através da ferramenta de análise de redes. (GIULIANI, 2010). Em outras palavras, a análise de redes sociais permite mensurar a hierarquia das conexões (relações) em determinado espaço ao longo do tempo, demonstrando a topologia singular e a evolução espacial das relações sem desconsiderar o processo a-determinístico e a distribuição estocástica.

Segundo, as redes de relacionamento são importantes já que se configuram como veículo de criação e de difusão de conhecimento. Os spillovers de conhecimento podem ser largamente atribuídos às redes de relacionamento e à mobilidade do trabalho (BOSCHMA; FRENKEN, 2010; ARAÚJO, 2013), principalmente em regiões que possuem como caraterística a proximidade geográfica entre firmas.

Terceiro, é importante enfatizar outra unidade de análise da GEE: a concentração espacial entre firmas. A aglomeração pode afetar o desenvolvimento, a evolução ou a queda de um setor. Essa relação recursiva possui pelo menos três dimensões: a concentração geográfica das atividades industriais (que pode gerar economias de aglomeração e arranques de novas firmas de inovação); a concentração geográfica das firmas (que aumenta a competitividade forçando a entrada e a saída de firmas e incrementando a performance das rotinas); a concentração espacial dos agentes (impulsionados pela proximidade entre firmas, que acaba afetando a ação coletiva, já que é mais provável que comportamentos oportunistas ocorram entre agentes próximos). (BOSCHMA; FRENKEN, 2010).

Nesse sentido, a proximidade tem uma importancia valiosa para a GEE, que defende esse efeito como elemento chave para explicar a performance e a formação da estrutura das redes de relações. (TORRE; RALLET, 2005). Evidências empíricas indicam os efeitos da proximidade como um drive relevante na evolução das redes de relacionamento (BROEKEL, 2015), sendo um pré-requisito para agentes se conectarem e para o aumento dos fluxos de conhecimento. Em essência, as questões de proximidade têm a capacidade de auxiliar no entendimento sobre a estrutura das redes (por que alguns indivíduos ou firmas estão melhores conectados que outros?), podem explicar os efeitos das interações (as relações de proximidade e de distância afetam a performance das firmas?) ou ainda contribuir com as dinâmicas de longo prazo das redes de interação e seu papel central na formação da topologia da rede de relacionamentos (qual o papel das diferentes proximidades no ciclo de vida de uma indústria?).

Essas questões possuem comportamento central para a análise da Geografia Econômica Evolucionária que procura explicar o desenvolvimento regional, local, setorial através da interação e da colaboração entre indivíduos e organizações. As firmas se diferem na forma como aprendem e por isso não se conectam facilmente e nem conseguem apender facilmente uma com as outras. Esse ponto indica 
que as relações entre firmas em geral e o conhecimento e a inovação, em particular, não são randomicamente estruturadas, mas, ao contrário, mostram-se enviesadas, ou seja, algumas firmas são mais conectadas que outras por razões que diferem. Compreender como os agentes interagem e colaboram pode ser a chave para desvendar como os laços são formados, como evoluem ao longo do tempo, como as regiões se diversificam, como instituições e a mudança institucional avança para o desenvolvimento e para o crescimento em setores, etc. A GEE entende que essa interação pode ser formada por similaridades: tecnológica, social, institucional, organizacinal ou geográfica. Em resumo, a contribuição que esse campo de estudo pode fornecer para desvendar a conexão espacial de conhecimento está centrada em: i) o conhecimento não “está no ar” e sim canalizado de forma seletiva e desigual no cluster; ii) a colaboração entre agentes é seletiva poque firmas e outros agentes têm diferente rotinas e capabilities; iii) várias proximidades são importantes drives para a formação de conexões, mas a proximidade per se não incrementa a performance da firma; iv) a relação que existe dentro de um cluster tem a tendência de se tornar introspectiva ao longo do tempo; v) relação externas do cluster são fundamentais para a manutenção da competitividade, mas necessitam de outras formas de proximidade para permitir a efetiva transmissão de conhecimento; e vi) mesmo em um local onde a proximidade geográfica e institucional formam um importante drive estimulando a relação em um cluster, nem todas as firmas apresentaão a mesma performance, mesmo considerando o mesmo meio ambiente institucional.

Em suma, para a GEE a relação dinâmica entre as formas de proximidade permite aprofundar a investigação da conexão entre a necessidade de interação, localização e processo inovativo, e essa abordagem analítica converge para o entendimento sobre a coordenação dos agentes. Por ser o elemento central da GEE é que serão abordadas as dinâmicas de proximidade na próxima seção.

\section{GEE e Dinâmicas de proximidade}

O conceito de proximidade é, atualmente, um tema amplamente discutido em diversos campos da ciência como, por exemplo, ciência regional, ciência organizacional e estudos sobre inovação. (KNOBEN; OERLEMANS, 2006) ${ }^{12}$. Suas ideias procuram desvendar o intricado processo inovativo que tem como hipótese central a necessidade de comunicação e interação entre agentes. A proximidade geográfica entra nesse mecanismo como um recurso capaz de diminuir as distâncias e facilitar a comunicação e a troca e geração de conhecimento ${ }^{13}$, tornando-se elemento importante para auxiliar na tomada de decisão dos atores em um ambiente de constante competitividade e cercado de incertezas. (BOSCHMA; FRENKEN, 2006; BOUBA-OLGA et al., 2015; CARRINCAZEAUX; LUNG; VICENTE, 2008; KNOBEN; OERLEMANS, 2006).

De maneira sintética, conforme Schiller (2004, p. 161),

[...] a passagem para o pós-fordismo e para as relações extremamente móveis traz como consequência a revalorização das dimensões locais. São as articulações dos fatores imateriais que formam os verdadeiros responsáveis por caracterizar as novas dinâmicas produtivas. Considerando essa hegemonia, os níveis de competitividade de uma firma dependem da relação entre os atores e da característica instalada no território [...].

Em suma, a proximidade per se faz referência à existência de interações (de natureza diversa) e recusa o apelo exclusivo dos custos de transporte da análise espacial, fundada sob o raciocínio baseado

\footnotetext{
12 O tema proximidade tem ampliado seu espaço no campo acadêmico e vem conquistando interesse nos periódicos especializados. Do ponto de vista cronológico, edições especiais foram publicadas no Revue d'économie régionale et urbaine (1993), L'industria (1998), Cambridge Journal of Economics (1999), Economie Rurale (2004), Economie et Institutions (2005), Regional Studies (2005) e Economie Régionale e Urbaine (2008). O tema tomou novas proporções quando tratado em conjunto com a perspectiva evolucionária na geografia econômica. Sob essa nova ótica, edições especiais podem ser conferidas no Journal of Economic Geography (2007), Economic Geography (2009), Regional Studies (2015) e Journal of Economic and Social Geography (2015).

13 Segundo Rallet e Torre (1999, apud FELDMAN, 1994, p. 1, grifo nosso), “[...] knowledge transverses corridors and streets more easily than continents and oceans $[\ldots]$...
} 
apenas na concepção física da relação. Essas interações podem ser de diversas maneiras: formais, informais, comerciais, complementares, adoção e difusão (de inovação), complementaridades (tecnológicas), etc. Ademais, a distinção entre interações intencionais e não intencionais não é trivial. (RALLET; TORRE, 1995). As análises de caráter não intencional têm origem nos trabalhos de Marshall (1920), com a noção dos efeitos externos presente nas aglomerações em nível local ${ }^{14}$. As análises de interação de natureza intencional são caracterizadas por trocas no mercado, relações de cooperação ou relações de parcerias e tratam das interações que se pretende estabelecer com outros parceiros (concorrência) podendo ser de confiança, informações ou técnicas, mas dizem respeito, sobretudo, às suas estratégias. (SCHILLER, 2004). Essa diferença de interação permite estabelecer, por exemplo, uma fronteira entre as relações que são inerentes ao cotidiano e aquelas que dependem das condições técnicas ou de distância e fundam, analiticamente, a introdução da ação de agentes econômicos na análise de proximidade. (RALLET; TORRE, 1995).

A frequência das interações também tem importância. Aqui está sinalizado o caráter dinâmico que contrasta com o aspecto estático da localização das firmas. É a partir da densidade e do prolongamento que se entendem as modificações e ajustes do sistema. Em outras palavras, é o dinamismo da interação que deixa claro o processo de separação e ligação ou proximidade e afastamento dos agentes, firmas, organizações, atividades, etc. (SCHILLER, 2004). Entender o número de interações, a forma como elas se reproduzem, sua perenidade e sua transversalidade se torna preocupação para qualquer pesquisador que pretende desvendar as relações de proximidade.

Em essência, diversas escolas frequentemente associam o papel da proximidade geográfica ao compartilhamento de conhecimento e à inovação. Apoiado no argumento que a troca de conhecimento tácito requer o contato face a face, existe uma ampla literatura que enfatiza a interação como um elemento altamente sensível à distância geográfica. A co-localização de firmas, portanto, pode oferecer vantagens competitivas para firmas e regiões. A literatura recente discute a existência de várias dinâmicas de proximidade, e diversos conceitos estão sendo propostos na literatura mundial como, por exemplo: proximidade cultural (GERTLER, 1995), proximidade social (UZZI, 1997), proximidade institucional (KIRAT; LUNG, 1999), proximidade ótima (NOTEBOOM,1999), proximidade organizada (RALLET, 2002), proximidade tecnológica (GREUNZ, 2003), proximidade cognitiva (GIULIANI; BELL, 2005), proximidade temporária (TORRE; RALLET, 2005), proximidade de status (GODART, 2012), proximidade mediada, proximidade relacional. (BOUBA-OLGA, GROSSETTI; FERRU, 2014) ${ }^{15}$.

Segundo a corrente evolucionária da geografia econômica, para o completo entendimento da dinâmica inovativa da firma devem-se considerar os estudos de proximidade em cinco dimensões: cognitiva, institucional, social, geográfica e organizacional. Essa classificação tornaria a pesquisa sobre as dinâmicas de proximidade mais analítica e se encaixaria na nova agenda promovida pelos especialistas interessados na mensuração e identificação dos tipos de proximidade entre agentes. Para Boschma (2005), essa delimitação abre um novo campo de pesquisa para a dinâmica inovativa quando trata a proximidade para além dos aspectos geográficos. Ademais, cinco proximidades possibilitam uma divisão das forças que induzem a localização de firmas e procura aprofundar o entendimento individual de cada componente no intricado mecanismo inovativo.

A proximidade cognitiva, diferentemente do sugerido por Arrow (1962), atualmente entende que o conhecimento não é um bem exógeno e de acesso livre na economia. Nelson e Winter (1982) defendem que o conhecimento é um recurso desenvolvido nos ambientes interno e externo da firma, que depende de sua potencialidade de acumular, desenvolver e absorver novas formas de aprender. Como resultado, a base cognitiva dos atores difere substancialmente em função do caráter heterogêneo. Isso implica que o

\footnotetext{
14 Para Marshall (1920) a co-localização de firmas é capaz de proporcionar ao espaço características importantes para o desenvolvimento local. Essa disposição acaba beneficiando as firmas com maiores oportunidades para a inovação do que se estivessem atuando isoladamente. A lógica presente nessa afirmação é que o conhecimento circula abertamente no espaço, produzindo novas fontes e novas gerações de processos e produtos. Essa estrutura cria os efeitos externos e permite que os segredos da profissão deixem de ser segredos e fiquem soltos no ar. Para um panorama geral sobre os efeitos de especialização e diversificação das regiões, fluxos de conhecimento e a sua relação com a inovação sugere-se Stefani e Lima (2014).

15 Para um maior aprofundamento sobre essas perspectivas sugere-se Knoben e Oaelermans (2006).
} 
conhecimento está disperso (na firma, nas organizações, na indústria), o que exige uma complicada capacidade de captar, organizar, decodificar, interpretar e recombinar para transformá-los em um novo conhecimento. (COHEN; LEVINTHAL, 1990). Por essa razão, a capacidade dos atores ou firmas de absorver novas tecnologias requer uma proximidade cognitiva, isto é, sua base cognitiva deve ser próxima o bastante de novos conhecimentos a fim de comunicar, processar e entender esses elementos com sucesso (BOSCHMA; LAMBOOY, 1999) ${ }^{16}$. Ademais, não se trata apenas de eficiência ou velocidade de aquisição de informação, mas, sobretudo, de ampliar o escopo e o espectro da cognição. (NOOTEBOOM, 1999). Em resumo, a proximidade cognitiva é capaz de facilitar a comunicação e ocorre de forma mais eficaz entre agentes que possuem a mesma capacidade de absorvê-la.

A proximidade organizacional está restrita à extensão das relações que são compartilhadas em um arranjo organizacional tanto dentro como entre organizações. Para a GEE, proximidade organizacional envolve taxa de autonomia e certo grau de controle que pode ser exercido pela organização nesse tipo de arranjo. Aqui, interessa o grau de interdependência estratégica que duas organizações possuem, já que essa relação reduz incertezas sobre o comportamento do parceiro nas relações. Em outras palavras, a proximidade organizacional é entendida como uma forma específica de proximidade entre firmas do mesmo grupo (subsidiárias, joint ventures, e outras relações de semelhança) que podem compartilhar conhecimento. O grau de proximidade organizacional é definido pelo aprofundamento da autonomia e controle induzido pela ligação entre as firmas. Quando atores compartilham uma alta proximidade organizacional, é fácil evitar os fluxos de conhecimento não intencional e reduzir as incertezas reduzindo também os custos de colaboração, favorecendo a troca de grupos de trabalho como engenheiros, pesquisadores, etc. (BALLAND, 2012).

A proximidade organizacional é entendida como benéfica para o aprendizado e inovação porque a criação de novo conhecimento acompanha incerteza e oportunismo. Para reduzir esses fatores, são elaborados, no mercado, mecanismos rígidos de controle (contratos, propriedade intelectual, etc.) e recompensas pelo investimento em nova tecnologia. Nas organizações esse mecanismo é percebido como custo de transação (COASE, 1937; WILLIAMSON, 1981) e, para sua redução, as relações entre organizações e intraorganizações são entendidas como alternativas viáveis.

A proximidade social tem origem em Granovetter (1985). Em essência, a literatura indica que as transações econômicas possuem, até certo ponto, influência das relações sociais enraizadas (embedded) no contexto local. Além disso, essa literatura sugere que quanto mais socialmente enraizada são as relações da firma, maior será o aprendizado interativo e a performance inovativa. Portanto, a proximidade social é definida como as relações sociais enraizadas (micronível) dos agentes e está voltada para confiança, amizade e experiência conjunta passada. A capacidade das organizações de aprender e inovar requer certa dose de proximidade social. A razão central está na ideia de que a confiança facilita a troca de conhecimento tácito, o que é, por natureza, o conhecimento mais eficaz para a ação inovativa e de maior dificuldade ${ }^{17}$. É importante salientar que a proximidade social não trata das situações em que pessoas compartilham valores (étnicos ou religiosos) que estão vinculados ao macronível (relacionado ao aspecto cultural e que será debatido na proximidade institucional). Centralmente, a proximidade social está interessada no papel exercido pela confiança que está positivamente relacionada com a lógica do encorajamento social e com a abertura da comunicação entre agentes. (BROEKEL; BOSCHMA, 2011).

Enquanto a proximidade social está definida como relações enraizadas entre indivíduos (micronível), a proximidade institucional está vinculada ao ambiente institucional (macronível), ou seja, instituições formais (leis e regras) e informais (hábitos e normas) que influenciam nas extensões e maneiras dos atores ou na coordenação das ações das organizações. Deve-se entender, portanto, a

\footnotetext{
16 Para Noteboom, (1999, p. 153, grifo nosso) “[...] Information is useless if it is not new, but it is also useless if it is so new that it cannot be understood [...]”.

17 Davids e Frenken (2015) classificam o conhecimento como analítico, sintético e simbólico. Especialmente de interesse para o campo das dinâmicas de proximidade, os autores defendem que as diferentes bases de conhecimento atuam diferentes papéis nos diferentes estágios da inovação. O conhecimento analítico pode estar ligado à proximidade cognitiva e à institucional. O conhecimento sintético pode se relacionar com a proximidade geográfica e à organizacional e o conhecimento simbólico pode estar relacionado às proximidades cognitiva, social e organizacional. Para maior aprofundamento sugere-se Davids e Frenken (2015).
} 
proximidade social, organizacional e institucional como formas de proximidade intimamente conectadas, em função do caráter e da influência dos regimes institucionais. A lógica por trás dessa afirmação é que as instituições podem permitir ou restringir mecanismos que afetem a transferência de conhecimento, o aprendizado interativo e a inovação. Em essência, a proximidade institucional é definida por restrição informal e regras formais compartilhadas entre atores e que representam de forma comum as rotinas e incentivos que permitem as organizações realizarem eficientemente a transferência de conhecimento. (BALLAND, 2012). Em outros termos, a noção de proximidade institucional inclui tanto a ideia de atores econômicos compartilhando as mesmas regras do jogo, como o conjunto de hábitos culturais e valores existentes. A linguagem comum, os hábitos compartilhados, o sistema de leis, as propriedades intelectuais, etc. formam a base para a coordenação econômica e para o aprendizado interativo. Em suma, a proximidade institucional permite condições estáveis para que o canal interativo se torne efetivo. (BOSCHMA, 2005). Para Gertler (1995), a informação é transmitida de forma mais eficiente em locais onde a cultura é próxima e a linguagem é comum aos atores.

Em termos analíticos, a GEE compreende a proximidade geográfica como a distância espacial ou física entre agentes econômicos de forma absoluta ou relativa. É importante deixar claro, desde o início, que a dimensão geográfica deve ser analisada isolada de outras formas de proximidade. Nesse caso, é possível afirmar que a transferência de conhecimento toma lugar sem a necessidade de interação ou coordenação entre agentes. O mecanismo por trás dessa afirmação está na ideia que o contato face a face proporcionado pela proximidade geográfica é o fator central no processo de transferência de conhecimento e informação. Em outras palavras, cada firma localizada em aglomerado pode se beneficiar da proximidade física das firmas instaladas nesse ambiente, e esse efeito, per se, torna-se o grande elemento da proximidade geográfica. (BOSCHMA, 2005).

Contudo, é difícil imaginar que processos imitativos possam ocorrer sem a proximidade cognitiva (em qualquer intensidade). Firmas necessitam de alguma capacidade (competência) para absorver e processar o conhecimento externo. Portanto, assume-se que a proximidade geográfica combinada com alguma proximidade cognitiva se torne suficiente para que o aprendizado ocorra. Hausmann (1996) vai além e indica que a proximidade geográfica pode apenas atuar como uma proximidade complementar no processo de aprendizado interativo, indicando que a proximidade social ou a proximidade organizacional podem ser mais importantes do que a proximidade física, mas entende que a proximidade geográfica pode facilitar a comunicação. O relativo consenso na literatura é que a proximidade geográfica atua como uma força complementar na construção das dinâmicas de proximidade social, organizacional, institucional ou cognitiva e facilita o aprendizado interorganizacional.

Importante ressaltar que a proximidade exagerada pode ser desfavorável para o aprendizado e para a inovação. Primeiro, há o risco do lock-in que ocorre nesse tipo de troca. Relações assimétricas conduzem a alta dependência de relações específicas, limitando o acesso a novas fontes de recurso e de informação. Para Boschma (2005, p. 65), “[...] search for novelty often requires going out of the established channels [...]”. Segundo, a implantação da novidade requer flexibilidade organizacional. A proximidade organizacional reflete uma hierarquia estrutural incapaz de oferecer flexibilidade para as ações. Quanto mais dependentes são as relações no arranjo organizacional, menores serão as iniciativas para além da relação, provocando efeitos negativos na flexibilidade e inovação. (BOSCHMA, 2005). Terceiro, relações em que existe a lealdade exagerada podem comprometer as ações dos atores que tendem a subestimar as oportunidades latentes. Para Uzzi (1997), um comportamento de muita lealdade pode desenvolver consequências negativas em um mundo onde ocorrem constantes mudanças tecnológicas, e onde o oportunismo é a conduta comum no mercado. Ainda, relações duradouras enclausuram os indivíduos às suas conexões e padrões sociais estabelecidos, aumentando o custo do aprendizado e da capacidade inovadora.

Finalmente, Boschma (2005) e Uzzi (1997) propõem a existência de um paradoxo de proximidade e apontam uma relação de " $U$ invertido" entre a proximidade e o desempenho inovativo da firma, 
indicando que existe um trade off entre essas dimensões e que, a partir determinado ponto, a proximidade deixa de ser um efeito benéfico e se torna um elemento negativo para a firma ${ }^{18}$. Em outras palavras, a capacidade adaptativa dos atores pode ser incrementada consideravelmente quando as relações consistem em um balanço entre manter a firma aberta (com a mente flexível) e construir relações de confiança (baixo custo de transação e troca de conhecimento confiável).

Finalmente, o quadro 2 apresenta a evolução cronológica das publicações que, de forma seminal, constroem o arcabouço teórico e que auxiliaram na composição das cinco dimensões propostas pela corrente evolucionária geográfica.

Quadro 1 - GEE e as dimensões de proximidade: revisão de literatura

\begin{tabular}{|c|c|c|c|c|}
\hline Autor & Jornal / Ano & $\begin{array}{c}\text { Elemento } \\
\text { Central }\end{array}$ & $\begin{array}{c}\text { Análise } \\
\text { Desenvolvida } \\
\end{array}$ & $\begin{array}{c}\text { Principais } \\
\text { Resultados } \\
\end{array}$ \\
\hline Granovetter, M. & $\begin{array}{l}\text { American Journal of Sociology } \\
\qquad 1973\end{array}$ & Vinculos Externos & $\begin{array}{l}\text { "Relações fracas" } \\
\text { estabelecidas com vínculos } \\
\text { externos podem ser } \\
\text { responsáveis por construir } \\
\text { ligações que beneficiam os } \\
\text { agentes }\end{array}$ & $\begin{array}{l}\text { Relaç̃̃es fracas são } \\
\text { reponsáveis por integrar } \\
\text { atores em outras } \\
\text { oportunidaes e comunidades }\end{array}$ \\
\hline Gertler, M.S. & $\begin{array}{l}\text { Economic Geography } \\
1995\end{array}$ & Proximidade Cultural & $\begin{array}{c}\text { Somente a proximidade física } \\
\text { não é capaz de traduzir a } \\
\text { dinâmica da inovação entre os } \\
\text { agentes. }\end{array}$ & $\begin{array}{c}\text { O sucesso no avanço de } \\
\text { novas tecnologias é devido a } \\
\text { proximidade cultural } \\
\text { (compartilhamento de } \\
\text { normas, códigos, linguagem e } \\
\text { prática) entre atores }\end{array}$ \\
\hline Uzzi, B. & $\begin{array}{c}\text { Administrative Sience } \\
\text { Quartely } \\
1997\end{array}$ & Proximidade Social & $\begin{array}{l}\text { As relações entre firmas } \\
\text { possuem laços de confiança, } \\
\text { transferência de informação e } \\
\text { resolução conjunta de } \\
\text { problemas }\end{array}$ & $\begin{array}{c}\text { Relaç̃oes baseadas em } \\
\text { estrutura social se mostram } \\
\text { duradouras e facilitam } \\
\text { performance inovativa. As } \\
\text { exceçס̃es aparecem com a } \\
\text { formação de "lock in". } \\
\end{array}$ \\
\hline $\begin{array}{l}\text { Kirat, T. } \\
\text { Lung, } Y \text {. }\end{array}$ & $\begin{array}{l}\text { European Urban and } \\
\text { Regional Studies } \\
1999\end{array}$ & Proximidade Institucional & Aprendizado institucional & $\begin{array}{l}\text { O contexto institucional cria } \\
\text { ambiente e regras que } \\
\text { influenciam e direcionam as } \\
\text { ações do indivíduo }\end{array}$ \\
\hline Nootebom & $\begin{array}{l}\text { Cambridge Journal of } \\
\text { Economics } \\
1999\end{array}$ & Proximidade Ótima & $\begin{array}{l}\text { Excessivo relacionamento } \\
\text { com o mesmo ambiente } \\
\text { (laços fortes) provoca } \\
\text { situaçós de "lock in". E } \\
\text { necessário o balanço entre } \\
\text { laços fortes e fracos } \\
\end{array}$ & $\begin{array}{c}\text { Trade-off entre distância } \times \\
\text { proximidade cognitiva se torna } \\
\text { elemento chave para } \\
\text { comunicação e geração de } \\
\text { inovações }\end{array}$ \\
\hline $\begin{array}{l}\text { Rallet, A. } \\
\text { Torre, A. }\end{array}$ & $\begin{array}{l}\text { GeoJournal } \\
1999\end{array}$ & $\begin{array}{l}\text { Proximidade Geográfica e } \\
\text { Não-Geográfica }\end{array}$ & $\begin{array}{c}\text { Insere conceitos de } \\
\text { proximidade organizacional } \\
\text { que se torna tão eficiente } \\
\text { quanto a proximidade } \\
\text { geográfica e que também é } \\
\text { capaz de desenvolver }\end{array}$ & $\begin{array}{l}\text { Relações "não locais" devem } \\
\text { ser encorajadas para o } \\
\text { desenvolvimento com a } \\
\text { mesma preocupação e } \\
\text { incentivos nas relações locais }\end{array}$ \\
\hline $\begin{array}{l}\text { Torre, A. } \\
\text { Gilly, J. P. }\end{array}$ & $\begin{array}{c}\text { Regional Studies } \\
1999\end{array}$ & $\begin{array}{l}\text { Proximidade Geográfica } \\
\text { Proximidade Organizacional }\end{array}$ & $\begin{array}{c}\text { Define proximidade } \\
\text { geográfica e organizacional e } \\
\text { discute o papel das } \\
\text { interações (não intencional e } \\
\text { voluntária) para as relações } \\
\text { de proximidade } \\
\end{array}$ & $\begin{array}{l}\text { Presença do contexto } \\
\text { institucional que influencia a } \\
\text { trajetória no processo de } \\
\text { desenvolvimento local. }\end{array}$ \\
\hline Howells, J. R. L. & $\begin{array}{l}\text { Urban Studies } \\
2002\end{array}$ & Aprendizado Cognitivo & $\begin{array}{l}\text { As interações são formadas } \\
\text { pelo tempo (força da } \\
\text { propagação) e influenciadas } \\
\text { pela geografia (formação } \\
\text { local, hábitos, conhecimento } \\
\text { de base,etc). }\end{array}$ & $\begin{array}{c}\text { O tempo é variável } \\
\text { determinante na transmição } \\
\text { de conhecimento } \\
\text { evidenciando que há limites } \\
\text { (força) para a utilização do } \\
\text { conhecimento. "U" shaped }\end{array}$ \\
\hline Greunz, L. & $\begin{array}{c}\text { Regional Science } \\
2003\end{array}$ & $\begin{array}{l}\text { Proximidade Tecnológica } \\
\text { Proximidade Geográfica }\end{array}$ & $\begin{array}{l}\text { A proximidade tecnológica é } \\
\text { tão importante quanto a } \\
\text { proximidade geográfica na } \\
\text { formação de conhecimento }\end{array}$ & $\begin{array}{c}\text { Os spillovers são } \\
\text { geograficamente } \\
\text { concentrados e dificilmente } \\
\text { ocorrem entre regiẽes } \\
\text { heterogêneas além de serem } \\
\text { melhor propagados pelo setor }\end{array}$ \\
\hline $\begin{array}{l}\text { Torre, A. } \\
\text { Rallet, A. }\end{array}$ & $\begin{array}{l}\text { Regional Studies } \\
2005\end{array}$ & Proximidade Temporária & $\begin{array}{c}\text { Empresas possibilitam } \\
\text { momentos de proximidade } \\
\text { temporária nas fases onde a } \\
\text { interação ou co-produção são } \\
\text { fundamentais }\end{array}$ & $\begin{array}{l}\text { Avanços das TICs e da } \\
\text { mobilidade aumenta a } \\
\text { possibilidade de coordenação } \\
\text { em longas distâncias }\end{array}$ \\
\hline $\begin{array}{l}\text { Giuliani, E. } \\
\text { Bell, M. }\end{array}$ & $\begin{array}{l}\text { Research Policy } \\
2005\end{array}$ & Proximidade Cognitiva & $\begin{array}{c}\text { Empresas são heterogêneas } \\
\text { e possuem diferentes base de } \\
\text { conhecimento }\end{array}$ & $\begin{array}{l}\text { A base e conhecimento é } \\
\text { elemento determinante para } \\
\text { firmas estabelecerem } \\
\text { relações individuais }\end{array}$ \\
\hline Boschma, R. A. & $\begin{array}{l}\text { Regional Studies } \\
2005\end{array}$ & $\begin{array}{l}\text { Proximidade Congitiva, } \\
\text { Organizacional, Social, } \\
\text { Intitucional e Geográfica }\end{array}$ & $\begin{array}{c}\text { Marco analítico das } \\
\text { dinâmicas de proximidade } \\
\text { para a GEE }\end{array}$ & $\begin{array}{c}\text { Definição e classificação das } \\
\text { cinco dimensões e } \\
\text { discussão sobre a relação } \\
\text { ótima de proximidade e seus } \\
\text { limites }\end{array}$ \\
\hline
\end{tabular}

Fonte: Elaborado pelos autores ${ }^{19}$.

\footnotetext{
${ }^{18}$ Weterings e Boschma (2009) no trabalho Does spatial proximity to costumers matter for innovative performance? Evidence from the Duch software sector os autores pesquisam os efeitos da aglomeração em determinado cluster de software e concluem que a proximidade social ou o processo de interação face a face com os agentes não pode ser exagerado, já que existem elementos que apresentam uma curva em U invertido, destacando que há um limite para a longevidade do modelo criativo baseado em relações tácitas.

19 Os autores agradecem as contribuições de Pierre-Alexandre Balland (Deputy-head of the Urban and Regional Centre of Utrecht Programme in Evolutionary Economic - Utrecht - Netherland) e Dieter Kogler (School of Geography - University College of Dublin - Regional Studies Editor) pela avaliação e aprovação do quadro além da indicação de literatura na composição do levantamento.
} 


\section{Considerações Finais}

A respeito das contribuições da GEE e das dinâmicas de proximidade para a discussão da mudança tecnológica, destaca-se que desde 1920, as questões sobre proximidade geográfica chamam atenção da literatura voltada para a compreensão da dinâmica industrial e de sistemas de produção. Nesse período, Marshall procurou compreender os efeitos das externalidades produzidos em aglomerados de firmas e sua relação com a atividade da indústria. Esse foco perde força após a emergência do modelo fordista, que destaca a grande firma como ator central da atividade produtiva, e que perdura até o período pós-guerra. A partir do declínio do bussines school, emergem alternativas às teorias do desenvolvimento da indústria e em meados da década de 1970, Piore, Becattini, Sabel, entre outros, demonstram extensivamente que existem modelos alternativos de organização industrial. Os avanços nessa área demonstram o que Marshall já havia percebido no início do século XX, ou seja, que a aglomeração de firmas pode ser capaz de introduzir inovações e se articular com o mercado diferentemente da percepção convencional baseada em economias de escala e altos investimentos em P\&D internos à firma.

É nesse novo cenário que as dinâmicas de proximidade se apresentam como elemento a ser desvendado. Com a escola francesa, a proximidade deixa de ser eminentemente geográfica e passa a ganhar novas dimensões e proposições. A relação dos agentes que antes era essencialmente espacial, agora leva em consideração também outros fatores como o aprendizado para desenvolvimento do produto (proximidade temporária), a introdução de uma nova tecnologia (proximidade tecnológica), etc. Contudo, fica claro que para ocorrer à inovação deve necessariamente haver, em alguma medida, a proximidade cognitiva.

Mesmo após avanços na área ainda é necessário um ardiloso caminho para desvendar por completo essa dinâmica. Em primeiro lugar é preciso compreender como se desenvolve a relação das dinâmicas de proximidade com o avanço dos meios tecnológicos de informação e comunicação (TICs). Em outros termos, as TICs serão capazes de encurtar distâncias e reduzir a necessidade da proximidade em um futuro próximo? Algumas pistas nesse sentido são propostas por Howells (2002) e Rallet e Torre (1999) que defendem a condição do contato pessoal (conhecimento tácito) como elemento central na difusão do conhecimento, sendo esse dificilmente substituído por ferramentas tecnológicas. Por outro lado, a nova geração avança de maneira surpreendente na relação e no manejo com os meios digitais aliado a taxas decrescentes dos custos de decodificação da informação. Johnson e Lybecker (2012) avaliaram por vinte anos a transferência de conhecimento biotecnológico e concluem que atualmente o conhecimento está mais propenso a percorrer grandes distâncias. Para os autores a padronização de produtos e o avanço dos meios de comunicação forma elementos que proporcionaram um salto na transferência de conhecimento para a indústria de artigos biotecnológicos. Huber (2012) chega a conclusões semelhantes pesquisando o cluster de Tecnologia da Informação (TI) de Cambridge na Inglaterra. $\mathrm{O}$ autor argumenta que a comunidade local não encontra benefícios reais na aglomeração de empresas para a troca de conhecimento. Doloreux e Shearmur (2011) também pesquisam a transferência de conhecimento em segmentos de capital intensivo e disparam conclusões semelhantes. Em suma, não deve ser renegado o avanço da sociedade, da relação precoce da nova geração com os novos meios de comunicação e da tecnologia para as questões de proximidade. Ademais, uma série de questões ainda permanece em aberto, como: para quais segmentos empresariais a proximidade é mais relevante?; o tamanho das firmas são relevantes para as desenvolver proximidades específicas?; que tipo de proximidade se beneficia com o avanço das TICs?

Em segundo lugar, os estudos estatísticos desenvolvidos na área apresentam resultados que ainda não são considerados robustos dentro do meio acadêmico. Desde o trabalho seminal de Jaffe (1993) ocorreram inúmeras tentativas de mensurar de forma cartesiana a formação dos knowledge spillovers e seu benefício nos Sistemas de Inovação. Broekel et al. (2014) apresentam diversos modelos que demonstram potencial para captar os fluxos de conhecimento e informação (modelo gravitacional, regressão quadrática múltipla, modelos de randomização exponencial e o modelo estocástico ator- 
orientado). Ter Wal e Boschma (2009) defendem que a análise de redes sociais emerge com uma importante alternativa para captar a interação e fluxo de conhecimento. Contudo, os resultados ainda se apresentam questionáveis. Aqui as críticas de Krugman (1991) que reivindica à comunidade acadêmica a necessidade de uma formalização e mensuração dos fluxos de conhecimento entendendo que "[...] knowledge flows are invisible, they leave no paper trail by which they may be measured and tracked [...]" parece fazerem sentido e esse é um grande desafio para o avanço dos pesquisadores da área.

Em terceiro lugar, as estatísticas além de mensurar as dinâmicas de proximidade precisam ter capacidade de identificar qual seu limite ótimo. Dito de forma diferente, se a proximidade é entendida como um elemento crucial na interação dos agentes para promover e trocar conhecimento, o seu excesso pode causar dano no desempenho inovativo. Boshma (2005) já alertava para a existência de um paradoxo da proximidade. Existem razões para acreditar que certa distância deve ser mantida para melhorar o aprendizado. Na construção de um novo conhecimento, é necessária uma ampla gama de informações desiguais que acabam desencadeando novas ideias e estimulando a criatividade. Sobre isso, a distância tem o potencial de estimular o novo, e a firma que possuir a capacidade de codificar as informações díspares e traduzir para seu benefício, também será capaz de sobressair no mercado. É difícil esquecer hábitos e rotinas que foram sucesso no passado, mas que acabam redundantes ao longo do tempo e podem levar a um processo de enclausuramento (lock in), no qual a rotina e a busca por métodos novos (porém similares) mantêm a trajetória encapsulada em uma única direção. Em suma, mais que mensurar a distância, se torna determinante achar a proximidade ótima para cada tipo de proximidade (social, cognitiva, institucional, organizacional e geográfica) e para cada segmento de indústria (bens de capital, tecnologia intensiva, serviços, etc.) tarefa que ainda precisa ser perseguida.

Em quarto lugar o desafio evolucionário. Partindo do pressuposto e dos conceitos da Geografia Econômica Evolucionária, a inovação surge a partir das microrrelações e, considera que entender as aglomerações significa entender as relações locais e globais entre indivíduos, instituições e sua coevolução. Experiências e competências adquiridas durante o tempo por indivíduos e instituições determinam a configuração presente e a trajetória futura de uma região. Para Padgett e Powel (2012) “in the short run, actors create relations; in the long run, relations create actors...”. É necessário desenvolver estudos que apreciem os resultados dinâmicos, onde a variável tempo ocupa papel central no processo e as questões de proximidade estão intimamente envolvidas. Em essência, o que se quer dizer é que para entender por completo o processo que envolve proximidade e laços de conhecimento é necessário uma mudança de perspectiva da condição estática para a dinâmica, isto é, somente o olhar temporal permitirá entender se a proximidade e redes de relações se reúnem por causa de um processo de selecção com base na decisão da organização, ou se a proximidade é uma construção social herdada de laços de conhecimento conjuntas.

Finalmente é importante salientar que as correntes geográficas existentes não levam em consideração a perspectiva evolucionária para o completo entendimento de questões como o progresso tecnológico geográfico, a dinâmica das vantagens comparativas, a reestruturação econômica da região e do crescimento econômico. Nesse contexto, a GEE promete investigar o mecanismo e o processo em que a economia se autotransforma a partir de dentro, de forma dinâmica, complexa e dependente do passado.

O campo de pesquisa para as dinâmicas de proximidade e para a Geografia Econômica Evolucionária apresenta uma fertilidade intelectual importante para o entendimento da dinamica inovativa. Ademais, a aproximação entre o campo neoclássico com a área institucional na geografia propõe o elemento apreciativo e ganhos intelectuais que uma escola de forma isolada não consegue oferecer. Como é usual em qualquer evolução, o tempo trará respostas que momentaneamente precisam ser reveladas. 


\section{Bibliografia}

AMIN, A.; THRIFT, N. What kind of economic theory for what kind of economic geography? Antipode, Malden, v. 32, n. 1, p. 4-9, 2000.

ARAÚJO, V. C. Dimensão local da inovação no Brasil: determinantes e efeitos de proximidade. Tese de Doutorado. Escola Politécnica da Universidade de São Paulo. São Paulo, 2013.

ARROW, K. Economic welfare and the allocation of ressources to invention. In: NELSON, R. (Ed). The rate and direction of inventive activity, NBER, Princeton, 1962.

AUTANT-BERNARD, C. The geography of knowledge spillovers and technological proximity. Institutions and Systems in the Geography of Innovation. New York, v 25, p. 181-197, 2002. Documento em PDF.

BALLAND,P. A. Proximity and the evolution of collaboration networks: evidence from research and development projects within the global navigation satellite system (GNSS) industry. Regional Studies, London, v. 46, n. 6, p. 741-759, 2012.

BARABÁSI, A. L. Linked: the new science of networks. Cambridge: Perseus Publishing, 2002.

BEAUDRY, C.; SCHIFFAUEROVA, A. Who's right, Marshall or Jacobs? The localization versus urbanization debate. Research Policy, [S.I.], v. 38, n. 2, p. 318-337, 2009.

BOSCHMA, R. A. Competitiveness of regions from an evolutionary perspective. Regional Studies, London, v. 38, n. 9, p. 1001-1014, 2004.

BOSCHMA, R. A. Proximity and innovation: a critical assessment. Regional Studies, London, v. 39, n. 1, p. 61-74, 2005.

BOSCHMA, R. A.; FRENKEN, K. The special evolution of innovative networks: a proximity perspective. In: BOSCHMA, R. A.; MARTIN, R. L. (Ed). The handbook of evolutionary economic geography, Edward Elgar, Cheltebham, 2010.

BOSCHMA, R. A.; FRENKEN, K. Why is economic geography not an evolutionary science? towards an evolutionary economic geography. Journal of Economic Geography, London, v. 6, p. 273-302, 2006.

BOSCHMA, R. A.; LAMBOOY, J. G. Evolutionary economics and economic geography. Journal of Evolutionary Economics, [S.I.], v. 9, n. 4, p. 411-429, 1999.

BOSCHMA, R. A.; MARTIN, R. L. The aim and scope of evolutionary economic geography. In: BOSCHMA, R. A.; MARTIN, R. L. (Ed). The handbook of evolutionary economic geography, Edward Elgar, Cheltebham, 2010.

BOSCHMA, R. Towards an evolutionary perspective on regional resilience. Regional Studies, London, V. 49, n. 5, p. 733-751, 2015.

BOSCHMA, R.; FRENKEN, K. Evolutionary Economic Geography. Papers in Evolutionary Economic Geography, Utrecht University, 2015.

BOUBA-OLGA, O. et al. Editorial: proximity dynamics, social networks and innovation. Regional Studies, London, v. 49, n. 6, p. 901-906, 2015.

BOUBA-OLGA, O.; GROSSETTI, M.; FERRU, M. How I meet my partner: reconsidering proximities. In: TORRE, A.; WALLET, F. (Ed). Regional development and proximity relation, Edward Elgar Publishing Limited, Cheltenham, 2014.

BRAKNMAN, S.; GARRETSEN, H. Rethinking the “new” geographical economics. Regional Studies, London, v. 37, n. 6, p. 637-648, 2003.

BRESCHI, S; LISSONI, F. Knowledge spillovers and local innovation systems: a critical survey. Industrial and Corporate Change, London, v. 10, n. 4, p. 975-1005, 2001.

BROEKEL, T. et al. Modeling knowledge networks in economic geography: a discussion of four methods. The Annals of Regional Science, [S.I.], v. 53, n. 2, p. 423-452, 2014.

BROEKEL, T. The co-evolution of proximities: a network level study. Regional Studies, London, v. 49, n. 6, p. 921-935, 2015.

BROEKEL, T.; BOSCHMA, R. Knowledge networks in the Dutch aviation industry: the proximity paradox. Journal of Economic Geography, London, v. 1, p. 1-25, 2011.

BRINCO, R. Velhos e novos caminhos da geografia da inovação. In: CONCEIÇÃO, O. A. C.; GRANDO, M. Z.; TERUCHKIN, S. U.; FARIA, L. A. E. (Org.). O ambiente regional. Porto Alegre: FEE, 2010. 
CARRINCAZEAUX, C.; LUNG, Y.; VICENTE, J. The scientific trajectory of the French School of Proximity: interaction- and institution-based approaches to regional innovation systems. European Planning Studies, [S.I.], v. 16, n. 5, p. 617-628, 2008. COASE, R. The nature of the firm. Economica, London, v. 4, n. 16, 1937.

COHEN, W. M.; LEVINTHAL, D. A. Absorptive capacity: a new perspective on learning and innovation. Administrative Science Quarterly, Michigan, v. 35, n.1, p. 128-152, 1990.

COTElo, F. C.; HERMANN, B. M.; GOLDBAUM, S. A controvérsia NEG x PEG: uma disputa metodológica no campo da geografia econômica. [S.l.], 2014. CRUZ, B. O.; FURTADO, B. A.; MONASTERIO, L.; JÚNIOR, W. R. (Ed). Economia regional e urbana: teorias e métodos com ênfase no Brasil, IPEA, Brasília, 2011.

DAVIDS, M.; FRENKEN, K. Proximity, knowledge base and the innovation process: the case of Unilever's Becel diet margarine. Papers in Evolutionary Economic Geography, Utrecht, n. 15.04, Nov. 2015..

DOLOREUX, D.; SHEARMUR, R. Collaboration, information and the geography of innovation in knowledge intensive business service. Journal of Economic Geography, London, v. 12, n. 1, p. 79-105, 2011.

DOSI, G.; SOETE, L. Technical change and international trade. In: DOSI, G.; FREEMAN, C.; NELSON, R.; SILVERBERG, G.; SOETE, L. (Ed). Technical change and economic theory, London Pinter, 1988. FELDMAN, M. P. The geography of innovation, Kluwer Academic Publisher, Dordrecht, 1994.

FUJITA, M.; THISSE, J. F. Economics of agglomeration: cities, industrial location and regional growth. Cambridge University Press, 2002.

GERTLER, M. S., "Being there": proximity, organization, and culture in the development and adoption of advanced manufacturing technologies. Economic Geography, Worcester, v. 71, n. 1, p. 1-26, 1995. Documento em PDF.

GIULIANI, E. Network dynamics in regional cluster: the perspective of an emerging economy. Papers in Evolutionary Economic Geography, Utrecht, n. 10, 14 Nov. 2010.

GODART, F. C. Trends networks: multidimensional proximity and the formation of aesthetic choice in the creative economy. Regional Studies, London, v. 49, n. 6, p. 973-984, 2015.

GONÇALVES, E.; FJARDO B. A. G., 2011. Influência da Proximidade Tecnológica e Geográfica sobre a Inovação Regional do Brasil. Revista de Economia Contemporânea, Rio de Janeiro, v 15, n 1, p. 112 142.

GRANOVETTER, M. Economic action and social structure: the problem of embeddedness. American Journal of Sociology, Chicago, v. 9, n. 3, p. 481-510, 1985.

GRANOVETTER, M. S. The strength of weak ties. American Journal of Sociology, Chicago, v. 8, n. 6, p. 1360-1380, 1973.

GREUNZ, L. Geographically and techonologically mediated knowledge spillovers between European regions. The Annals of Regional Science, [S.I.] v. 37, p. 657-680, 2003.

HAUSMANN, U. Neither industrial district nor innovative milieu: entrepreneurs and their context. An actor-oriented framework and case studies from Greater London and Zurich. $36^{\circ}$ European Regional Science Association, Zurique, Suíça, 1996.

HODGSON, G. M. Institutional economics: surveying the "old” and the "new”. Metroeconomica, [S.I.]. v. 44, n. 1, p. 1-28, 1993. Documento em PDF.

HOWELLS, J. R. L. Tacit knowledge, innovation and economic geography. Urban Studies, v. 39, p. 871-884, 2002.

HUBER, F. Do Cluster Really Matter for Inovation Practices in Information Technology? Questioning the Significance of Technological Knowledge Spillovers. Journal of Economic Geography, 12, p. 107126, 2012.

JAFFE, A. B.; TRAJTENBERG, M.; HENDERSON, R. Geographic localization of knowledge spillovers as evidenced by patent citations. Quarterly Journal of Economics, Oxford, v. 108, n. 3, p. 577-598, 1993. 
JOHNSON, D. K. N.; LYBECKER K.M . Does distance matter less now? The changing role of geography in biotechnology innovation. Review of Industrial Organization, 40, p. 21-35, 2012.

KIRAT, T.; LUNG, Y. Innovation and proximity: territories as loci of collective learning process. European Urban and Regional Studies, London, v. 6, n. 1, p. 27-38, 1999.

KLEPPER, S. The evolution of the U.S. automobile industry and Detroit as its capital. [S.I.], 30 Dec. 2001 Paper presented at 9th Congress of the International Schumpeter Society, Gainesville..

KNOBEN, J.; OERLEMANS, L. A. G. Proximity and inter-organizational collaboration: a literature review. International Journal of Management Reviews, [S.I.], v. 8, n. 2, p. 71-89, 2006.

KOGLER, D. F. Editorial: evolutionary economic geography - theoretical and empirical progress. Regional Studies, London, v. 49, n. 5, p. 705-711, 2015. KRUGMAN, P. R. Increasing returns and economic geography. Journal of Political Economy, Chicago, v. 99, n. 3, p. 483-499, 1991.

MARSHALL, A., 1920. Principles of Economics, MacMillan, London.

MARTIN, R. L.; SUNLEY P. The place of path dependence in a evolutionary perspectiveon the economic landscape. In: BOSCHMA, R. A.; MARTIN, R. L. (Ed). The handbook of evolutionary economic geography, Edward Elgar, Cheltebham, 2010.

METCALFE, J.S. Institution and progress. CRIC discussion paper, Manchester, n. 45, 2001.

NEARY, P. Of hype and hyperbolas: introducing the new economic geography. Journal of Economic Literature, Pittsburgh, v. 39, n. 2, p. 536-561, 2001.

NELSON R., WINTER, S. An evolutionary theory of economic change, Cambridge Massachussets and London, England. The Belknap Press of Harvard University Press, 1982.

NELSON, R. R. Recent evolutionary theorizing about economic change. Journal of Economic Literature, Pittsburgh, v. 33, p. 48-90, 1995.

NOTEBOOM, B. Innovation, learning and industrial organization. Cambridge Journal of Economics, London, v. 23, p. 127-150, 1999.

RALLET, A. Economia da proximidade: em direção a um balanço. Cadernos IPPUR, Rio de Janeiro, ano 16, n.2, p. 59-80, 2002.

RALLET, A.; TORRE, A. Economie industrielle et economie spatial, Paris: Economica, 1995.

RALLET, A.; TORRE, A. Is geographical proximity necessary in the innovation networks in the area of global economy? GeoJournal, [S.I.], v. 49, n. 1, p. 373-380, 1999.

RUFFONI, J.; SUZIGAN, W. Inovação Tecnológica de Firmas em Sistemas Locais de Produção: a realidade dos produtores de máquinas para calçados do Rio Grande do Sul. Ensaios FEE (Impresso), v. 33, p. 1005-1036, 2016.

SCHILLER, M. C. O. S. Regulação dos territórios e dinâmicas institucionais da proximidade. Cadernos IPPUR, Rio de Janeiro, ano 18, n. 1-2, p. 161-179, 2004.

SCHUMPETER, J. A. Capitalism, socialism and democracy. New York: Harper, 1942.

SIMON, H. A. A behavioral model of rational choice. Quarterly Journal of Economics, Oxford, v. 6, p. 99-118, 1955.

STEFANI, R.; LIMA, J. J. M. Proximidade geográfica e fluxos de conhecimento: uma metanálise possível sobre os novos achados na construção da dinâmica inovativa. [S.l.], 2014. Trabalho apresentado no $7^{\circ}$ Encontro de Economia Gaúcha, Porto Alegre, 2014.

TER WAL, A. L. J.; BOSCHMA, R. A. Applying social network analysis in economic geography: theoretical and methodological issues. The Annals of Regional Science, [S.I.], v. 43, n. 3, p. 739-756, 2009

TORRE, A.; GILLY, J. P. On the analytical dimension of proximity dynamics. Regional Studies, London, v 34, n. 2, p. 169-180, 1999.

TORRE, A.; RALLET, A. Proximity and Localization. Regional Studies, London, v. 39, n. 1, p. 47-59, 2005..

UZZI, B. Social Structure and competition in interfirm networks: the paradox of embeddedness. Administrative Science Quartely, v. 42, n. 1, p. 35-67, 1997.

WETERINGS, A.; BOSCHMA, R. Does spatial proximity to costumers matter for innovative performance? Evidence from the Duch software sector. Research Policy, [S.I.], v. 38, n. 5, p. 746-755, 2009. 
WILLIAMSON, O. E. The economics of organization: the transaction cost approach. American Journal of Sociology, Chicago, v. 87, n. 3, p. 548-577, 1981. 